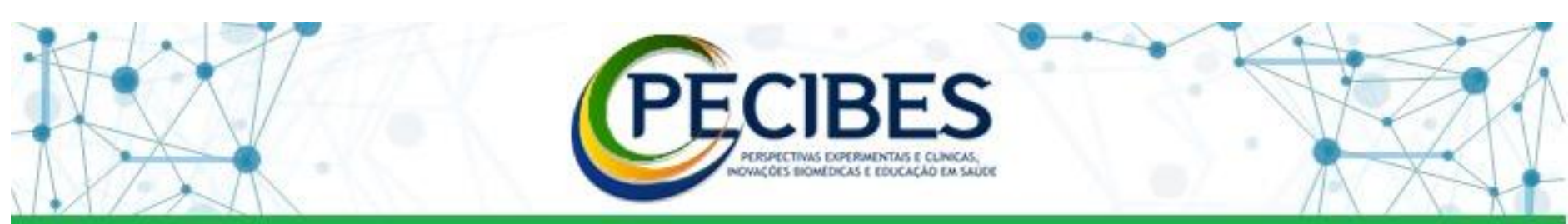

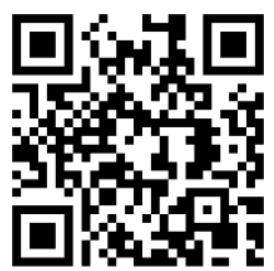

http://www.seer.ufms.br/in dex.php/pecibes/index

* Autor

correspondente:

Sidney Afonso Sobrinho Junior Universidade Federal de Mato Grosso do Sul - UFMS. E-mail do autor: sidney.junior@ufms.b $\mathrm{r}$

Descritores:Exercício Aquático.Amputação. Equilíbrio Postural.

Key-words: Aquatic Exercise. Amputation Postural, Balance. Terapiapor, Ejercicio, acuático, Amputación., Equilibrio, ,postural..

\section{Influência do exercício aquático na funcionalidade, dor e equilíbrio postural na amputação unilateral de membro inferior: Estudo Piloto.}

Influence of aquatic exercise on functionality, pain and postural balance in unilateral lower limb amputation: pilot study.

Solange Evangelista dos Santos Carvalho ${ }^{1}$, Fábio Roberto Barbosa Saiki², Patrícia de Moraes Ferreira Brandão ${ }^{1}$, Paulo Henrique Muleta Andrade ${ }^{2}$, Thomaz Nogueira Burke ${ }^{3}$.

1. Fisioterapeuta no CER/APAE e mestrando(a) do Programa de Pós -Graduação do Mestrado em Ciênciasdo Movimento da UFMS, Campo Grande /MS.

2. Fisioterapeuta, Doutor, Coordenador Técnico no CER/APAE e Pós -Doutorando do Programa de Pós -Graduação do Mestrado em Ciências do Movimento da UFMS, Campo Grande /MS.

3. Fisioterapeuta, Doutor, Orientador do Programa de Pós -Graduação do Mestrado em Ciências do Movimento da UFMS, Campo Grande /MS

Introdução: A amputação é um procedimento cirúrgico, cuja intenção é promover perspectivas em relação a função e melhorar o estado de saúde do indivíduo amputado. Dentre as propostas de tratamento a Fisioterapia Aquática (FA) associa a cinesioterapia aos princípios fisicos da água e apresenta evidências de eficácia ao tratamento das disfunções relacionados ao equilíbrio e tem por objetivo otimizar e acelerar o processo de recuperação funcional dos pacientes amputados, todavia há poucos estudos envolvendo amputados tratados com exercício em imersão. Objetivo: Avaliar a influência do exercício aquático na funcionalidade, dor e equilíbrio postural na amputação unilateral de membro inferior. Material e Métodos: Projeto foi aprovado pelo CEP 4.897.547, foi avaliado indivíduo com amputação transtibial (Diabetes Mellitus). A intervenção foi realizada em piscina coberta e aquecida a $32,5^{\circ} \mathrm{C}$, na profundidade do processo xifóide, pelo período de 8 semanas, na frequência de 2 vezes semanais e com duração de 40 minutos. Foi realizada avaliação do equilíbrio (BERG e plataforma de equilíbrio estático), escala funcional da dor e medida de independência funcional (MIF).Resultados: $\mathrm{Na}$ avaliação pré intervenção foram identificadas BERG 11, MIF 85, Escala Funcional de dor 1, Elipse de Confiança $(302,6)$ e deslocamento total de 229, na avaliação pós intervenção foram identificados BERG 13, MIF 117, Escala Funcional de dor 1, Elipse de Confiança (200,7), deslocamento total 43,8. A escala de equilíbrio de BERG houve melhora de 5\%, MIF aumentou 25,4 \%. Na Plataforma de Equilíbrio K Force Plates apresentou melhora de 101,9 pontos na elipse de confiança e 85,8 pontos no deslocamento total do centro de gravidade. Conclusões: Os exercícios aquáticos (nessa frequência, duração e intensidade) proporcionaram diminuição do deslocamento total do eixo de gravidade na postura estática, causou melhor distribuição do peso entre retropé e antepé dessa forma aumentou a independência funcional do indivíduo amputado. 